blue clay, this is apparently not the magma in which crystallisation originally took place, for the diamonds may have been forced into the clay by volcanic agencies. Actual blocks of one of the original rocks in which crystallisation took place have been found in blue clay. These blocks consisted of an eclogite containing large quantities of iron, and small diamonds were found, thus suggesting that such was the original mode of formation of the diamond.

F. M. P.

\section{PICTOGRAPHS OF ARROWS IN FRENCH} CAVES.

$T$ HE mural paintings and engravings of the Pyrenean caves is the subject of a series of memoirs by Prof, E. Cartailhac and l'Abbé H. Breuil, now appearing in l'Anthropologie. In the current number is an account of the "Grotte des Forges" at Niaux, Ariège. The cave is a narrow gallery more than $1400 \mathrm{~m}$. in length, with several short branches; at 6 I $\mathrm{m}$. from the entrance a broad lateral gallery runs due south for a distance of $160 \mathrm{~m}$., and terminates in a rotunda, the walls of which are decorated with bisons, horses, deer, wild goats, and groups of signs. There are no designs of animals in the first half of the main gallery, and only five at long intervals in the second. The authors write with enthusiasm concerning the rotunda. The paintings possess to a supreme

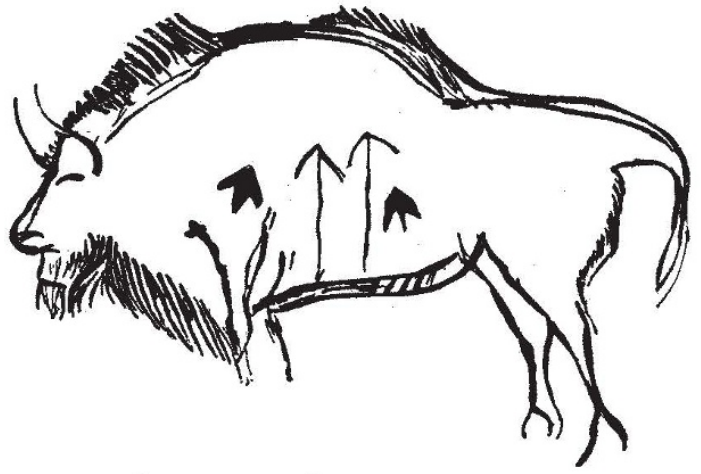

Bison in the Salon noir of Niaux transfixed by three arrows.

degree the style of the period, and represent the same animals that were familiar to the Palæolithic artists of the Pyrenees, the bisons being in the great majority. The drawings, which represent animals in profile, are drawn with a brush in black pigment with a sure and exact touch, and the characteristic traits of the animals are conscientiously delineated. The best polychrome frescoes are to be seen in the caves at Altamira, in Spain, but Niaux is unexcelled in its line work. The black pigment consisted of a mixture of charcoal and oxide of manganese worked up with grease.

Perhaps the most important new feature of the Niaux pictographs is the representation of arrows sticking into many of the animals, thus conclusively proving the existence of the bow and arrow at this early period. The accompanying figure represents a large bison with four arrows, the two lateral being red in colour. Some of the animals are marked by a spot, which may be intended to represent a wound.

A lamp placed on the ground in a corner of the rotunda or "salon noir" revealed, by chance, a series of engravings on the firm clay soil of the cave. The same animals that were painted on the walls were also engraved on the ground. The drawings were of the same style, and some of the animals were pierced with arrows. But it was only on the ground that designs of fish occurred, one of which, $30 \mathrm{~cm}$. in length, is readily recognised as a trout. Even some impressions of the naked feet of the artists were still visible. Of definite objects very little has as yet been discovered, only one small flint scraper of characteristic Palæolithic type, and fragments of bones, pieces of yellow ochre, and ashes. To execute the painting the Cave-men must have had artificial light of some sort.

The sign-pictographs are obscure in their significance. Some look like feathers with long quills; possibly they are arrows, in which case the arrows were feathered. There are several straight or slightly curved broad lines, from near the end of which a prominence is depicted; these appear to represent stone implements let into a thick stick. Other sticks or clubs are straight or slightly curved; these the authors regard as boomerangs. Other markings consist of lines or groups of spots, some of a red colour arranged in a circle surrounding a central spot. These recall the markings on the coloured pebbles of the famous cave of Mas d'Azil.

These discoveries by our French colleagues are shedding welcome light upon the life of the Palzolithic cave-dwellers of western Europe, but doubtless more information will come to hand when the investigation of the wonderful French caves is completed.

A. C. $\mathrm{H}$.

\section{NOTES}

Sir George Darwin, K.C.B., F.R.S., has been elected a foreign member of the Amsterdam Academy of Sciences.

THE "Società italiana delle Soienze (detta dei XL.)," of which Prof. Cannizzaro is president, has elected Sir William Ramsay as a foreign fellow (Socio straniero).

THE annual conversazione of the Royal Society of Arts will be held at the Natural History Museum, South Kensington, on Thursday next, July 2.

We learn from the British Medical Journal that Prof. Grassi, whose name is well known in the scientific world in connection with research on malaria and other subjects, has been created a Senator of the kingdom of Italy.

THE annual meeting of the Victoria Institute will be held at Burlington House on Wednesday, July 15. The chair will be taken by the president, the Earl of Halsbury, F.R.S., and an address will be given by Mr. E. Walter Maunder.

THE council of the Royal Society has awarded the Mackinnon studentships for the year 1908 as follows :one in physics to Mr. J. A. Crowther, of St. John's College, Cambridge, for an investigation of the passage through matter of the $\beta$ rays from radio-active substances; one in biology to Mr. D. Thoday, of Trinity College, Cambridge, for a research into the physiological condition of starvation in plants and its relation to the responsiveness of protoplasm to stimulation, especially to stimuli affecting respiration.

Mr. A. G. Bagshawe, the director of the Sleeping Sickness Bureau, who can be addressed care of the Royal Society, Burlington House, London, W., desires it to be known that he will be glad to receive reprints of any papers dealing with sleeping sickness, trypanosomiasis, and cognate subjects, and, indeed, any information relating to the work of the bureau.

Reuter's Agency learns that a fresh commission is being organised to proceed to East Africa to study sleeping sickness, its object being to continue the work carried

$$
\text { NO. } 2017 \text {, VOL. 78] }
$$

